\begin{tabular}{|c|c|c|c|}
\hline \multirow{2}{*}{$\begin{array}{r}\text { Case Reports in } \\
\text { Gastroenterology }\end{array}$} & \multicolumn{2}{|c|}{ Case Rep Gastroenterol 2015;9:194-199 } & \multirow[b]{2}{*}{$\begin{array}{l}\text { Karger } \\
\text { Open'access }\end{array}$} \\
\hline & $\begin{array}{l}\text { DOI: } 10.1159 / 000431307 \\
\text { Publisnea onine: June 5, } 2015\end{array}$ & $\begin{array}{l}\text { (C) } 2015 \text { S. Karger AG, Basel } \\
1662-0631 / 15 / 0092-0194 \$ 39.50 / 0 \\
\text { www.karger.com/crg }\end{array}$ & \\
\hline & \multicolumn{2}{|c|}{$\begin{array}{l}\text { This is an Open Access article licensed under the terms of the Creative Commons } \\
\text { Attribution-NonCommercial } 3.0 \text { Unported license (CC BY-NC) (www.karger.com/OA } \\
\text { license), applicable to the online version of the article only. Distribution permitted for non } \\
\text { commercial purposes only. }\end{array}$} & \\
\hline
\end{tabular}

\title{
Wilkie's Syndrome or Superior Mesenteric Artery Syndrome: Fact or Fantasy?
}

\author{
Vera Zaraket Liliane Deeb \\ Staten Island University Hospital, Staten Island, N.Y., USA
}

\section{Key Words}

Wilkie's syndrome $\cdot$ Superior mesenteric artery syndrome $\cdot$ Intestinal obstruction $\cdot$ Weight loss

\begin{abstract}
Superior mesenteric artery (SMA) syndrome (known as Wilkie's syndrome) is a rare cause of upper gastrointestinal obstruction. It is an acquired disorder in which acute angulation of the SMA causes compression of the third part of the duodenum between the SMA and the aorta. This is commonly due to loss of fatty tissue as a result of a variety of debilitating conditions. We report a 17-year-old female who presented with intermittent abdominal pain and intractable vomiting following significant weight loss after hospitalization for pneumonia. Symptoms persisted for 2 years and the patient underwent extensive invasive and non-invasive tests, but to no avail. Thereafter she developed acute high intestinal obstruction, which unraveled her diagnosis. This case emphasizes the challenges in the diagnosis of SMA syndrome and the need for increased awareness of this entity. This will improve early recognition in order to reduce irrelevant tests and unnecessary treatments. $\quad 2015 \mathrm{~S}$. Karger AG, Basel
\end{abstract}

\section{Introduction}

Superior mesenteric artery (SMA) syndrome, also called Wilkie's syndrome or cast syndrome, is a rare disorder in which acute angulation of the SMA causes compression of the third part of the duodenum between the SMA and the aorta, leading to obstruction. SMA syndrome is an atypical cause of proximal intestinal obstruction, most frequently occurring in young patients who have had an important weight loss. Surgeries for spinal deformities as well as high insertion of the ligament of Treitz are other potential causes for the occurrence of SMA syndrome $[1,2]$. Loss of retroperitoneal fatty tissue as a result of this variety of con-

KARGER 125/s $\quad \begin{aligned} & \text { Dr. Vera Zaraket } \\ & \text { Staten Island University Hospital } \\ & 1359 \text { Richmond Road, First Floor } \\ & \text { Staten Island, NY 10304 (USA) } \\ & \text { E-Mail vera-zaraket @ hotmail.com }\end{aligned}$


Zaraket and Deeb: Wilkie's Syndrome or Superior Mesenteric Artery Syndrome: Fact or Fantasy?

ditions is believed to be the etiologic factor causing the acute angulation. Symptoms vary from postprandial nausea and bilious vomiting to abdominal pain as well as weight loss and can occur acutely or chronically [3]. The severity of the symptoms largely depends on the degree of the compression as reflected by the aortomesenteric angle.

SMA syndrome was first described by the Austrian professor Carl Freiherr von Rokitansky in 1861 as an autopsy finding [4]. Later, Wilkie provided a more detailed clinical and pathophysiologic description in a series of 64 patients and suggested treatment approaches [5]. After that, a controversy regarding the actual existence of this syndrome started, especially because of the lack of specificity of the symptoms and the long list of differential diagnoses. However, advances in imaging, such as in computed tomography (CT) and magnetic resonance imaging, have tremendously helped with clear visualization of the angle between the aorta and the SMA and thus improved the diagnostic rate [6]. In adults, clinical SMA syndrome manifestations appear if the angle drops below $20^{\circ}$, and it is believed that values of this angle may be lower for pediatric patients [5]. Thus, in the appropriate clinical context, detailed history as well as imaging findings should highly raise the clinical suspicion for the diagnosis of SMA syndrome. A delay in this diagnosis can potentially lead to many complications, such as electrolyte imbalance, catabolic wasting, peritonitis and gastric perforation.

Conservative therapy mainly consists of weight gain achieved orally or parenterally, with the aim of restituting the mesenteric fat pad and increasing the aortomesenteric angle [7]. If this non-invasive approach fails, surgical therapy may be the next approach, with duodenojejunostomy being the currently preferred treatment [8].

In this paper, we describe a case of SMA syndrome in a young female with characteristic symptoms of duodenal obstruction, whose diagnosis was delayed for 2 years. That led to multiple office and emergency room visits, along with poor quality of life until the diagnosis was made and surgical treatment performed. Identification of this underestimated syndrome can be a diagnostic dilemma and is frequently delayed. We present this case to heighten the awareness of this syndrome and the need for early management to prevent diagnosis delay and serious complications.

\section{Case Report}

A 17-year-old female presented to the emergency room with persistent dull epigastric abdominal pain, severe bloating, inability to sense hunger, early satiety, postprandial fullness and intermittent non-bloody vomiting of 2 years duration that had worsened at the time of presentation. She had also experienced abdominal discomfort with exercise and quit gymnastics. The patient had irregular bowel movements, but usually every 4 days with the help of laxatives. She denied fever, chills, jaundice, diarrhea or any sick contacts. She reported having suffered from these complaints shortly after hospitalization for complicated pneumonia 2 years before, when she had lost about 40 pounds $35 \%$ of the her initial weight). Extensive investigation, including laboratory testing, imaging, upper gastrointestinal endoscopy and colonoscopy, had been performed repetitively and reported unremarkable. She has tried proton pump inhibitors, gluten-free diet and lactose-free diet without any improvement.

At presentation to our institution, the patient's vital signs were within normal limits. She looked anxious and her physical examination was unremarkable except for a firm diffusely tender and distended abdomen with distended stomach boundaries on percussion. Laboratory evaluation at admission was normal except for elevated bicarbonate ( $31 \mathrm{mmol} / \mathrm{l})$ consistent with emesis and contraction alkalosis. White blood cell count was $5,000 / \mathrm{mm}^{3}$, hemo- 
Zaraket and Deeb: Wilkie's Syndrome or Superior Mesenteric Artery Syndrome: Fact or Fantasy?

globin $12 \mathrm{~g} / \mathrm{dl}$, sodium level $140 \mathrm{mmol} / \mathrm{l}$, potassium $4 \mathrm{mg} / \mathrm{dl}$, blood urea level $18 \mathrm{mg} / \mathrm{dl}$ and creatinine $0.75 \mathrm{mg} / \mathrm{dl}$. The liver profile was normal with AST $26 \mathrm{IU} / \mathrm{l}$, ALT $21 \mathrm{IU} / \mathrm{l}$, total bilirubin $0.4 \mathrm{mg} / \mathrm{dl}$ and alkaline phosphatase $26 \mathrm{IU} / \mathrm{l}$. A CT scan of the abdomen and pelvis showed an acute angle of $10^{\circ}$ between the SMA and the aorta, with impression upon the anterior third part of the duodenum (fig. 1). Severe dilatation of the stomach and proximal duodenum above the bifurcation was noted, in addition of an SMA-aorta distance of $5.5 \mathrm{~mm}$ (fig. 2), consistent with the diagnosis of SMA syndrome.

Gastrointestinal barium series showed severely delayed transit through the third part of the duodenum, with to-and-fro peristalsis consistent with partial bowel obstruction at this level (fig. 3). The patient was placed in the prone position, which facilitated the distal progression of the oral contrast material. She was managed conservatively over 3 weeks with peripheral parenteral nutrition and gastric decompression via a nasogastric tube, followed by placement of a Dobhoff catheter for post-pyloric feeding. She tolerated oral diet in the form of fractionated meals 4 weeks later and was discharged with outpatient follow-up and weight monitoring. However, conservative management failed a few months later and the patient presented again to the emergency department with diffuse abdominal pain and nonbloody vomiting. At this point, a surgical evaluation was obtained and the patient received a duodenojejunostomy without duodenal mobilization. She did well after the surgery, as her symptoms resolved and she started to gain weight.

\section{Discussion}

SMA syndrome is a rare pathology with an incidence that ranges between 0.013 and $0.3 \%$ [7]. The defining feature of this entity is upper gastrointestinal obstruction caused by compression of the third part of the duodenum between the SMA anteriorly and the aorta posteriorly [9]. In humans, the aorta-SMA angle ranges from 38 to $65^{\circ}$, due to the erect posture, while in quadrupeds, it is nearly a right angle [10]. The main anatomic feature of SMA syndrome is a narrowing of the aorta-SMA angle to $<25^{\circ}$, and as a result, the aortomesenteric distance decreases to $<10 \mathrm{~mm}$, from normally 10 to $28 \mathrm{~mm}$ [9].

Etiological factors can be either a congenital or an acquired anatomic abnormality or, more commonly, a debilitating condition causing severe weight loss. Congenital etiologies include abnormally low insertion of the SMA or high insertion of the angle of Treitz dislocating the duodenum to a cranial position. Acquired anatomic abnormalities can occur following corrective spinal surgery such as scoliosis surgery by a relative lengthening of the spine [11], spinal trauma, and after abdominal surgery such as total proctocolectomy and ileal J-pouch anal anastomosis due to tension and caudal pull of the small bowel mesentery [12]. Severe weight loss, as in our patient, leading to a depletion of the fatty cushion around the SMA is a major cause of SMA syndrome. Catabolic states like burns [13], eating disorders such as anorexia nervosa [14], or wasting conditions such as neoplastic diseases and malabsorptive states are the most commonly reported reasons of drastic weight loss [9].

Patients with SMA syndrome may present acutely, with chronic insidious symptomatology, or with an acute exacerbation of chronic symptoms. Acute presentation is usually characterized by signs and symptoms of duodenal obstruction. Chronic cases like our patient may present with long-standing vague abdominal symptoms or recurrent episodes of abdominal pain, associated with vomiting. Other less common symptoms are esophageal reflux, early satiety with a sensation of fullness owing to increased gastroduodenal transit time, and gastric distension $[8-11,15]$. 
Zaraket and Deeb: Wilkie's Syndrome or Superior Mesenteric Artery Syndrome: Fact or Fantasy?

The diagnosis of the SMA syndrome is challenging and often delayed due to its insidious presentation. High clinical suspicion is warranted and diagnosis is based on clinical evidence supported by radiological findings. Barium radiography demonstrates dilatation of the first and second part of the duodenum with or without gastric dilatation, anti-peristaltic flow of barium proximal to the obstruction and a delay of 4-6 $\mathrm{h}$ in gastroduodenojejunal transit time, with relief of obstruction when the patient is placed in the prone, knee-chest or left lateral position [7, 8]. Contrast-enhanced CT or magnetic resonance angiography enable visualization of the vascular compression of the duodenum and precise measurement of the aortomesenteric angle and distance. Endoscopic examination may visualize a pulsatile extrinsic compression suggestive of this condition [16].

Traditionally treatment has consisted of conservative measures such as gastric decompression, parenteral nutrition and/or post-pyloric feeding when possible, followed by oral diet as tolerated [7]. Posturing maneuvers during meals and motility agents may be helpful in some patients. No time limit has yet been defined for the medical treatment. Surgery may be considered if conservative treatment fails [8]. Duodenojejunostomy is the operation of choice to relieve the obstruction, with a success rate up to $90 \%$ [8]. Another less invasive surgical option, known as Strong's procedure, involves lysis of the ligament of Treitz with mobilization of the duodenum; however, this operation had a failure rate of $25 \%$ [9]. Gastrojejunostomy, a previously reported surgical treatment, has been abandoned because of increased postoperative complications like blind loop syndrome and recurrence of symptoms due to non-decompression of the duodenum.

\section{Conclusion}

We feel that SMA syndrome is underdiagnosed. High clinical suspicion is of utmost importance, especially in patients with severe weight loss and symptoms of gastric distension. Surgical stress should as well be considered as a trigger factor of SMA syndrome. Interdisciplinary teamwork provides the most beneficial diagnostic and therapeutic result in this often underestimated disease. Lastly, we would like to point out the difficulty of achieving an accurate diagnosis of SMA syndrome in an atypical clinical setting similar to what happened in our case. Heightened awareness is advised for early recognition to avoid unnecessary suffering for the patient.

\section{References}

-1 Strong EK: Mechanics of arteriomesenteric duodenal obstruction and direct surgical attack upon etiology. Ann Surg 1958;148:725-730.

2 Sapkas G, O’Brien JP: Vascular compression of the duodenum (cast syndrome) associated with the treatment of spinal deformities. A report of six cases. Arch Orthop Trauma Surg 1981;98:7-11.

-3 Record JL, Morris BG, Adolph VR: Resolution of refractory superior mesenteric artery syndrome with laparoscopic duodenojejunostomy: pediatric case series with spectrum of clinical imaging. Ochsner J 2015;15:74-78.

4 von Rokitansky C: Lehrbuch der pathologischen Anatomie, vol 3, ed 3. Vienna, Braumüller und Seidel, 1861, p 87.

5 Wilkie D: Chronic duodenal ileus. Am J Med Sci 1927;173:643-649.

-6 Unal B, Aktaş A, Kemal G, Bilgili Y, Güliter S, Daphan C, Aydinuraz K: Superior mesenteric artery syndrome: CT and ultrasonography findings. Diagn Interv Radiol 2005;11:90-95.

7 Welsch T, Buchler MW, Kienle P: Recalling superior mesenteric artery syndrome. Dig Surg 2007;24:149156.

-8 Mandarry M, Zhao L, Zhang C, Wei Z: A comprehensive review of superior mesenteric artery syndrome. Eur Surg 2010;42:229-236. 


\section{Case Reports in
Gastroenterology}

\begin{tabular}{l|l}
\hline Case Rep Gastroenterol 2015;9:194-199 \\
\hline DOI: 10.1159/000431307 & $\begin{array}{l}\text { ○ } 2015 \text { S. Karger AG, Basel } \\
\text { www.karger.com/crg }\end{array}$ \\
\hline
\end{tabular}

Zaraket and Deeb: Wilkie's Syndrome or Superior Mesenteric Artery Syndrome: Fact or Fantasy?

-9 Merrett ND, Wilson RB, Cosman P, Biankin AV: Superior mesenteric artery syndrome: diagnosis and treatment strategies. J Gastrointest Surg 2009;13:287-292.

10 Ahmed AR, Taylor I: Superior mesenteric artery syndrome. Postgrad Med J 1997;73:776-778.

11 Tsirikos AI, Anakwe RE, Baker AD: Late presentation of superior mesenteric artery syndrome following scoliosis surgery: a case report. J Med Case Rep 2008;2:9.

$\$ 12$ Ballantyne GH, Graham SM, Hammers L, Modlin IM: Superior mesenteric artery syndrome following ileal J-pouch anal anastomosis. An iatrogenic cause of early postoperative obstruction. Dis Colon Rectum 1987;30:472-474.

13 Reckler JM, Bruck HM, Munster AM, Curreri PW, Pruitt BA Jr: Superior mesenteric artery syndrome as a consequence of burn injury. J Trauma 1972;12:979-985.

$\$ 14$ Verhoef PA, Rampal A: Unique challenges for appropriate management of a 16-year-old girl with superior mesenteric artery syndrome as a result of anorexia nervosa: a case report. J Med Case Rep 2009;3:127.

15 Reynolds EW, Kinnard TB, Kriss VM, Perman JA: Superior mesenteric artery syndrome: an uncommon cause of feeding intolerance in infancy. J Pediatr Gastroenterol Nutr 2008;46:92-95.

16 Gustafsson L, Falk A, Lukes PJ, Gamklou R: Diagnosis and treatment of superior mesenteric artery syndrome. Br J Surg 1984;71:499-501.

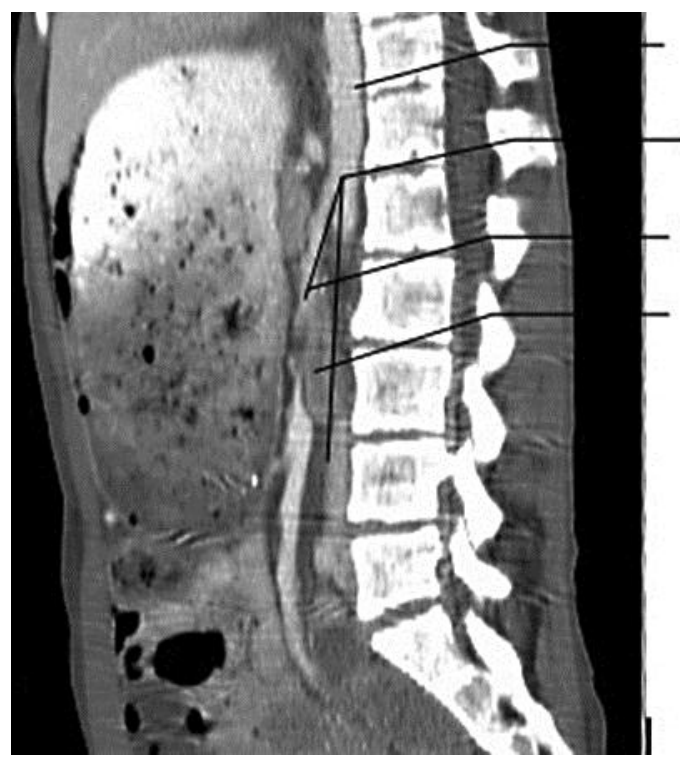

\section{Aorta}

Aorta-SMA angle

SMA

\section{Duodenum}

Fig. 1. Sagittal CT image showing the entrapment of the duodenum between the aorta and the SMA with an aorta-SMA angle of $10^{\circ}$. 


\begin{tabular}{|c|c|c|}
\hline \multirow{3}{*}{$\begin{array}{l}\text { Case Reports in } \\
\text { Gastroenterology }\end{array}$} & \multirow{2}{*}{\multicolumn{2}{|c|}{ Case Rep Gastroenterol 2015;9:194-199 }} \\
\hline & & \\
\hline & DOI: $10.1159 / 000431307$ & $\begin{array}{l}\text { (C) } 2015 \text { S. Karger AG, Basel } \\
\text { www.karger.com/crg }\end{array}$ \\
\hline
\end{tabular}

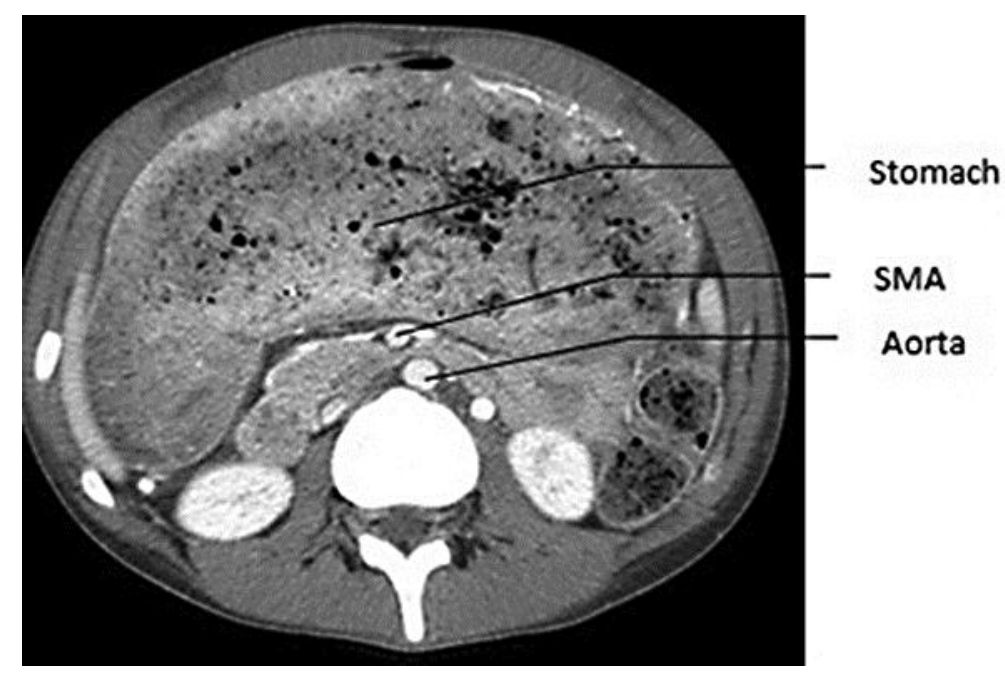

Fig. 2. CT scan showing the SMA and the aorta separated by a small distance of $5.5 \mathrm{~mm}$ and severe gastric distension.

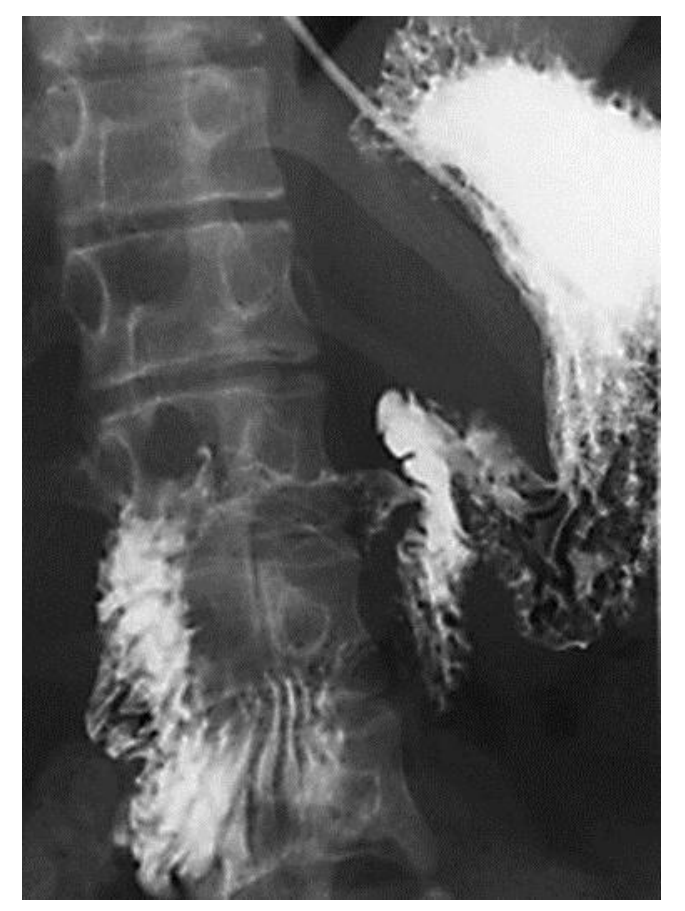

Fig. 3. Barium study showing delayed transit through the third part of the duodenum. 